\title{
Brazilian Portuguese version of financial risk-taking and tolerance scales: validity evidence within and between measures
}

\author{
Versão brasileira das escalas de propensão e tolerância ao risco financeiro: \\ evidências de validade intra e entre medidas
}

Anna Beatriz Howat-Rodrigues, ${ }^{1}($ D $)$ José Henrique Benedetti Piccoli Ferreira, ${ }^{2}$ (D) Jerson Laks ${ }^{1,3,4}$ (D)

\begin{abstract}
Objectives: To construct and validate a psychological measure called the Financial Risk-Taking Scale (FRTakS) and to translate, adapt, and validate a psychological measure called the Financial Risk Tolerance Scale (FRTolS) with a Brazilian sample. Exploratory and confirmatory factor analyses were used to assess evidence of the validity of the scales' internal structures. We also tested the convergent validity between FRTakS and FRTolS.

Method: After construction (FRTakS) and adaption (FRTolS), the instruments were evaluated by expert judges for the relevance of their items to the scales, followed by pretesting. A crosssectional study was then conducted using a convenience sample of 834 people who responded to invitations sent to a mailing list or to an online invitation on the Brazilian Securities and Exchange Commission website (Comissão de Valores Mobiliários [CVM]).

Results: Mean age of participants was 39.27 years (standard deviation $[S D]=10.82)$, they had high educational level $(60.9 \%$ post-graduate), were married or living together (60\%), and their spending power was $41.36(S D=13.27)$. Exploratory and confirmatory analysis identified two factors in FRTakS (Investment and Spending Money), both with 4 items; and identified a single factor in FRTolS, comprising 7 items.

Conclusion: Reliability indexes for the goodness of fit of the factor structure were satisfactory. There was a positive and significant correlation between the FRTakS Investment factor and FRToIS, confirming convergent validity. The results suggest the existence of a two-dimensional factor structure for FRTakS, and a one-dimensional factor structure for FRTolS. The instruments also exhibited convergent validity with each other.

Keywords: Risk behavior, weights and measures, psychometrics, qualitative evaluation, psychological tests.
\end{abstract}

\section{Resumo}

Objetivos: Construir e validar uma medida psicológica denominada Escala de Propensão ao Risco Financeiro (FRTakS), e também traduzir, adaptar e validar uma medida psicológica denominada Escala de Tolerância ao Risco Financeiro (FRTolS) em uma amostra brasileira. Evidências de validade interna foram avaliadas com base em análise fatorial exploratória e confirmatória. Além disso, verificamos a validade convergente entre FRTakS e FRTols.

Método: Após a construção (FRTakS) e adaptação (FRTolS), os instrumentos passaram pela etapa de avaliação por juízes especialistas sobre a relevância dos itens para a escala e estágio de pré-teste. Um estudo transversal foi realizado com uma amostra de conveniência de 834 pessoas que responderam a convites enviados para uma lista de e-mails, ou a convites on-line publicados no site da Comissão de Valores Mobiliários (CVM). Resultados: Os participantes tinham idade média de 39,27 anos [desvio padrão $(D P)=10,82$ ], alta escolaridade $(60,9 \%$ pósgraduação), eram casados ou viviam juntos (60\%), e tinham poder de compra de $41,36(\mathrm{DP}=13,27)$. A análise exploratória e confirmatória identificou dois fatores para FRTakS, cada um com 4 itens (Investimento e Gastar Dinheiro); e indicou 1 fator para FRTolS composto por 7 itens.

Conclusão: A estrutura fatorial apresentou boa adequação, com índices de confiabilidade satisfatórios. Foi encontrada uma correlação positiva e significativa entre o fator FRTakS Investimento e a FRTolS, confirmando a validade convergente. Os resultados sugerem a existência de uma estrutura fatorial bidimensional para FRTakS, e uma estrutura fatorial unidimensional para FRTolS. Além disso, os instrumentos mostraram validade convergente entre eles.

Descritores: Assunção de riscos, pesos e medidas, psicometria, análise qualitativa, testes psicológicos.

\footnotetext{
${ }^{1}$ Instituto de Psiquiatria - Universidade Federal do Rio de Janeiro (IPUB-UFRJ), Rio de Janeiro, RJ, Brazil. ${ }^{2}$ Universidade de São Paulo (USP), São Paulo, SP, Brazil. ${ }^{3}$ Universidade do Grande Rio, Duque de Caxias, RJ, Brazil. ${ }^{4}$ Universidade do Estado do Rio de Janeiro (UERJ), Rio de Janeiro, RJ, Brazil. Submitted Aug 12 2018, accepted for publication Feb 232019.

Suggested citation: Howat-Rodrigues AB, Ferreira JHBP, Laks J. Brazilian Portuguese version of financial risk-taking and tolerance scales: validity evidence within and between measures. Trends Psychiatry Psychother. 2019;41(4):318-326. http://dx.doi.org/10.1590/2237-6089-2018-0066
} 


\section{Introduction}

The perspective on risk-taking in finance considers it to be an individual inclination, in a given context, to choose risky options over safer ones. The risky option is defined by its multiple possible outcomes while the safe option is defined by a single predicted outcome. ${ }^{1}$ Within the aspect of individual inclination, previous researches have pointed out that individual financial risk tolerance is an important variable that influences financial decision-making, especially in the context of uncertainty. Financial risk tolerance is related to how much a person can bear possible losses or to the volatility of a choice. ${ }^{2}$ Risk-taking and risk tolerance are directly and positively associated constructs, since risk tolerant individuals tend to engage in more risky behaviors. ${ }^{3} \mathrm{~A}$ theoretical model proposed by Grable ${ }^{4}$ predicts that risk tolerance works as a mediator between risk profile, risk perception, risk need, and choice of risky behavior.

In general, there is an ongoing discussion on the difficulties of studying risk-taking, since there is no agreement on standardizing instruments and establishing convergent validity between them. One reason for this difficulty is that risk-taking is a multideterminant phenomenon that is influenced by risk tolerance, the context in which decisions are taken, personality traits, and sociodemographic data such as gender and age. ${ }^{3,5-7}$

Use of scales to measure risk-taking has been expanding, with a domain-specific approach that presupposes multiple dimensions of risk related to different contexts, rather than using generalized risktaking scores. Researchers have tried to adapt the concept of the Domain-specific Risk-Taking Scale (DOSPERT) $^{8}$ for the Brazilian culture. ${ }^{6,7}$

The DOSPERT is a North American instrument that aims to measure risk-taking as risk attitudes, defined as how much an individual would engage in risky behavior; and perceived-risk attitudes, defined as the willingness to engage in a risky activity as a function of its perceived riskiness. The two parts of the scale have 40 and 30 items. Participants rate on 5-point or 7-point Likert scales the extent to which they perceive an item to be risky (from "Not at all risky" to "Extremely risky") and how likely they would be to engage in the activity or behavior (from "Extremely unlikely" to "Extremely likely"). ${ }^{9}$

The original scale covered five factors identified based on a review of the literature on risk-taking behaviors: ethical, financial, health/safety, recreation, and social (see the original paper ${ }^{8}$ for descriptions of each factor). The financial factor is subdivided into gambling and investment items. In the original version, ${ }^{8}$ this factor had 8 items with Cronbach's alpha (a) ranging from 0.69 to 0.84 for the Perceived-risk attitudes scale, and from 0.72 to 0.77 for the Risk attitude scale. In the second version, the factor had 6 items: 3 on gambling and 3 on investment. The reliability data from English-speaking participants had better statistical indices: English a > 0.80 ; French $a$ in the range of 0.68 to 0.77 .

Brazilian studies have also used DOSPERT to measure risk-taking. However, it has been shown that the Brazilian Portuguese version of DOSPERT has a different factor structure to the original English version. The ethical/legal risk factor did not group items in the Brazilian version, while items were grouped in such a way that a substance abuse risk-taking factor emerged. The instrument presented moderate statistical indicators for reliability. ${ }^{7}$

Data on financial risk-taking in the Brazilian context, collected using DOSPERT, ${ }^{8}$ identified a financial factor composed of four items ( $a=0.55)$. This instrument, called the Specific Risk-Taking Scale, was administered to 394 people and based on the results of the first study, a version was constructed consisting of 14 selfassessed items with 5-point Likert response scales (from "would never do" to "would always do"). ${ }^{6}$ The scale was later administered to 1.244 people who answered both the risk-taking scale and an online sociodemographic questionnaire. ${ }^{7}$ The authors proposed a new instrument called the Specific Risk-Taking Scale - Evolutionary Domains, with different DOSPERT factors: 7 items in a Cohesion factor $(a=0.82)$ and 7 in a Competition/ Fertility factor $(a=0.60)$. Financial items were part of Competition/Fertility factor.

Silva et al. ${ }^{10}$ produced a free translation of financial items from the Perceived-risk Attitudes Scale and obtained an instrument composed of 8 items, like DOSPERT, ${ }^{8}$ with an overall a of 0.79: 4 items in a Spending factor; 3 items in an Investment factor; and 1 item, "Investing in stocks," that loaded onto both factors. The divergent results found in previous studies using DOSPERT ${ }^{8}$ indicate a need to reassess the items in each factor and to develop items that correspond to the nature of the risk construct in the Brazilian population. ${ }^{6,7}$

In common with risk-taking, a variety of instruments have been used to measure the risk tolerance construct, such as the Dilemmas of Choice, Theory of Expected Utility, scalar measures, heuristics, and subjective evaluation. ${ }^{4,5}$ Of note among the scalar instruments is the Financial Risk Tolerance Scale developed by Grable and Lytton. ${ }^{5}$ These authors created 100 initial items that were reduced to 13 after studies of scale construction and validity. The 13 items were grouped onto three factors: Investment Risk ( $a=0.72$ ), Risk Comfort \& 
Experience $(a=0.50)$ and Speculative Risk $(a=0.44)$. Each item presented up to four possible contextualized answers, and received scores ranging from 1 to 4 to make up a final score.

Gava \& Vieira ${ }^{11}$ conducted translation and adaptation of this instrument into Brazilian Portuguese, resulting in eight items distributed into three different factors: Investment Risk \& Risk Comfort \& Experience; Risk as comfortable choice; and Speculative Risk (a are not described; $53.24 \%$ variance explained). In a comparison of Brazilian and North American samples, data showed a factorial structure of 4 factors in both countries, but the item distribution was different: one factor without a description, a risk factor of allocation of assets, another of lifestyle as game, and risk by prospect theory; a values for each factor are not reported, but and the combined scale had a of $0.71 .^{2}$ These findings provided evidence that there was variation in risktolerance attitudes between Brazilians and Americans. Brazilians were more risk tolerant than Americans and more likely to allocate investments aggressively. Grable and Lytton's scale ${ }^{5}$ is widely used, but the reliability of the items and their factor structure needs to be better explored, mainly for Brazilian samples.

One important issue concerns the content of instruments that measure risk tolerance. ${ }^{12}$ Almost all instruments contain items related to asset allocation decisions but leave aside other important factors such as the influence of emotion, environmental factors, and others. Taking this into account, one study ${ }^{12}$ aimed to evaluate the determinants of risk tolerance in a Brazilian sample. The results showed that emotion and cognitive biases such as self-attribution, excessive trust, and cognitive dissonance, among others, were significant. In addition to this, Kannadhasan ${ }^{3}$ aimed to examine the role of demographic factors in combination as a differentiating factor among levels of risk tolerance and risk behavior of Indian retail investors. Data showed the importance of gender, age, education, and occupation to understanding profiles of risk tolerance and risk behavior.

It is clear from the above that there are instabilities in the factors and item reliability of risk-taking and risk tolerance measures used in Brazil. Thus, this study aimed to construct and validate a psychological measure called the Financial Risk-Taking Scale (FRTakS) and to translate, adapt, and validate a psychological measure called the Financial Risk Tolerance Scale (FRTolS) ${ }^{5}$ for Brazilian Portuguese. Exploratory factor analysis (EFA) and confirmatory factor analysis (CFA) were used to assess evidence of the validity of the internal structure of both scales. We also tested the validity of measures analyzing convergent validity between FRTakS and FRTols, hypothesizing a positive association. ${ }^{3}$ Additionally, the hypothesis is that these instruments will have satisfactory indicators of internal validity and that there will be convergence between them.

Regarding the factor structures of these scales, we do not expect to find the same structure as instruments administered to samples from developed countries, because country conditions may have an influence on risk. ${ }^{2,13,14}$ In a study ${ }^{13}$ about age patterns in risk-taking propensity and real-world risk taking, researches examined a sample of 5227 individuals from 11 Western and non-Western countries. They argued that the ways risk is defined in each culture, norms concerning adolescent behavior, and varying opportunities for engaging in various types of risky behavior were important variables for understanding differences in real-world risk taking. The real risks analyzed were related to health risks, such as patterns of alcohol/drug use and sexual activity. Also, individuals who live in countries with a higher Human Development Index (HDI) have a lower propensity for risk-taking. Along the same lines, Mata et al. ${ }^{14}$ surveyed data from 77 countries indicating that countries in which HDI are lower were characterized by higher levels of risk taking. This influence occurs because the level of hardship found in a country contributes to earlier maturation of organisms and consequently affects the age-risk relationship and the perception of what is risky. ${ }^{14}$

\section{Methods}

\section{Participants}

Pre-test participants were 4 females and 6 males, mean age of 43.3 years (standard deviation $[S D]=12.82$ ), and average spending power of $39.0(\mathrm{SD}=10.04)$.

A cross-sectional study was conducted with a convenience sample of 834 people, mostly male $(68.3 \%)$ who responded to an invitation sent to the Securities and Exchange Commission of Brazil (Comissão de Valores Mobiliários [CVM]) mailing list or an online invitation on the website. The mean age of participants was 39.27 years (SD $=10.82)$, educational level was high $(60.9 \%$ post-graduate), most were married or living together $(60 \%)$, and mean spending power was 41.36 (SD = 13.27).

\section{Instruments}

\section{Sociodemographic data}

A sociodemographic questionnaire was used in all steps of the research and included questions addressing sex, age, schooling, marital status, and spending power measured using the Brazilian Economic Criteria. ${ }^{15}$ We 
used these criteria as a continuous measure on which the participants could score from 0 to 100 points, depending on their answers; the higher the score the higher the consumption of goods and the educational level of the participant/family.

\section{Risk-taking}

The initial instrument consisted of 18 items, originating from the following scales:

1) Eight items from the DOSPERT ${ }^{9}$ financial factor, translated into Portuguese. ${ }^{16}$

2) Four items from the Specific Risk Propensity Scale. ${ }^{6}$

3) We also used three items developed by the authors, but these were excluded after statistical analysis, considering our objective of constructing a new instrument.

3) Three items from the Specific Risk Propensity Scale - Evolutionary Domains. ${ }^{7}$

As mentioned, the factor structure of this instrument did not include a specific factor for financial risk-taking, but we selected three items related to financial topics, which were part of the Competition/Fertility factor.

\section{Risk tolerance, ${ }^{5}$ translated into Portuguese ${ }^{2}$}

This instrument consists of 13 self-assessed items with differing numbers of response choices per item. Each choice is scored on an increasing scale of risk tolerance ranging from 1 to 4 . We used 10 items from this scale after 3 of the Speculative Risk items were excluded because of a low a value (0.44). Furthermore, answers to 3 items were reformulated, because they only had 3 response options, while the other items of the scale had 4, since this kind of difference could contribute to loss of statistical quality.

\section{Procedures for evaluating the quality of FRTakS and FRTols items}

A financial risk-taking scale (FRTakS) was built and a foreign scale used to measure risk tolerance (FRTolS) was adapted to Portuguese. The initial items were shown to two judges working in the education department at the CVM. These judges were requested to judge the relevance of each item in each factor of the FRTakS and the FRTolS. The judges were also asked to contribute any other items that they deemed appropriate.

At this stage, agreement regarding FRTolS was $100 \%$. Regarding FRTakS, the CVM judges agreed that 2 items did not reflect the proposed risk-taking dimension and so these items were removed. A further 9 items had $100 \%$ agreement. The CVM judges disagreed about the other 4 items, about betting, and the judges also pointed out that these items were very similar, differing only in terms of the type of bet (e.g. horse race, lottery, etc.), so we decided to combine all 4 items into a single item. They also proposed adding 7 new items about risk-taking in everyday decisions. This stage resulted in an instrument with 17 items. We changed the name of the factors, based on this new item structure. We retained the Investment factor and we replaced the Gambling factor with a Spending Money and Loans factor.

Next, the instruments resulting from this initial stage were sent to 4 different judges (specialists and researchers on the subject of risk), who were given the same judgment task for the items resulting from the previous analysis. Items that achieved a rate of agreement of less than $75 \%$ were removed from the final instrument.

At this stage, the rate of agreement on the FRTols was once more $100 \%$. With relation to the FRTakS, the judges completely agreed on the pertinence of 10 items. Three items had $75 \%$ agreement and were retained. Four items were removed because they did not reach a minimum agreement of $75 \%$. The resulting instrument had 13 items.

Finally, we performed the pretest. The items on the scale were read to 10 representatives of the target population. We read the items in a group, out loud, and the participants were asked to explain what they understood from each item. Only one item on each scale presented difficulty in understanding and needed reformulation as suggested by the participants.

Thus, the FRTakS consisted of 13 items: 5 items were expected to load onto an Investment factor and 8 items onto a Spending Money and Loans factor. The FRTolS consisted of 10 items: 5 items on an Investment Risk \& Risk Comfort \& Experience factor; and 5 on a Risk as Comfortable Choice factor.

\section{Ethical considerations}

This study complies with ethical guidelines and was approved by the institutional review board at Instituto de Psiquiatria - Universidade Federal do Rio de Janeiro (IPUB-UFRJ; protocol no. 58096816.0.0000.5263). The authors informed the participants about the study aims. Participants provided consent signing free and informed consent forms.

\section{Data analysis}

Data were analyzed using the Statistical Package for Social Sciences (SPSS) version 21.0, FACTOR 10.3.01, and Mplus 7.4. The database was randomly divided using an SPSS function into two databases of the same size (approximately $50 \%$ of cases in each). The dimensional structure of the instruments was tested in part of the 
sample using EFA and reliability indexes were computed for the items of the resulting subscales. Aiming to verify the factorial adequacy of the data, we performed an unweighted least squares (ULS) factor analysis for both instruments using the oblique rotation method (PROMIN), which assumes a correlation between the resulting factors. ${ }^{17}$ We also used the Hull method to attempt to find alternative models, based on balance between model fit and number of parameters. ${ }^{18}$ Internal consistency was calculated as the a reliability indices for each of the independent factors.

CFA was conducted using the second part of the database. The method of estimation to verify goodnessof-fit for the models proposed by CFA was weighted least squares mean- and variance-adjusted (WLSMV), designed specifically for non-continuous data that may not be multivariate normal.17,18 The quality of the overall adjustment of the factor model was verified according to the indices and their respective recommended reference values, as follows: a) $X^{2}$ (chi-square) - goodness-offitness index; b) comparative fit index (CFI) - comparative indicator concerning goodness of fit of models (>90); c) Tucker-Lewis index (TLI) or non-normed fit index (NNFI) - relative fit indices that compare the target model with the null model ( $>90)$; d) root mean square error of approximation (RMSEA) - large sample residual analysis indicator (<.08 with confidence interval of $90 \%$ ); and e) weighted root mean square residual (WRMR) - average differences between the sample and estimated population variance and covariance $(<1.0) .{ }^{19}$

\section{Results}

\section{Psychometric properties analysis for the FRTakS}

EFA of the main scale components was performed with the first half of the sample. Hull analysis suggested a two-dimensional solution as the most parsimonious. In the analysis with two factors, five items had factor loadings below 0.40 , and were eliminated from the analysis. The final analysis with extraction of the two factors returned adequate data for both factors ${ }^{18,19}$ [Kaiser-Meyer-Olkin $(\mathrm{KMO})=0.66$; Bartlett's test of sphericity: $\left.\mathrm{X}_{28,417}^{2}=442.9 ; \mathrm{p}<0.001\right]$. The FRTakS factors (Table 1 ) were named as follows: Spending Money (Factor 1), and Investments (Factor 2).

The second database was analyzed with CFA. The model being tested was the factor structure that emerged from the exploratory step.

The initial model did not achieve satisfactory adequacy ratios $\left[X^{2}=129.057, d f=19(p<0.001) ; C F I=0.83\right.$; TLI $=0.74 ; \operatorname{RMSEA}(90 \% \mathrm{CI})=0.118(0.099-0.138)$; WRMR $=1.439]$. Seeking to improve the fit of the model, we analyzed the modification indices (MI) in order to identify suggestions of correlation between the error (residue) parameters of pairs of items, or the existence of crossed loadings, analyzing indices that had values above 11. Elevated MI were found for the relationships F1-RT11 $=49.28$, e4-e8 $=18.18$ and F2-RT7 = 37.59. Control of this parameter allowed us to achieve better fit and adequacy for the model $\left[X^{2}=26.79\right.$, df $=16$ ( $p$ $=0.044) ; \mathrm{CFI}=0.98 ; \mathrm{TLI}=0.97 ; \operatorname{RMSEA}(90 \% \mathrm{CI})=$ 0.040 (0.007-0.066); WRMR $=0.596]$.

As shown in Figure 1, the correlation between factors was $r=0.001$. The reliability indexes were similar to those found for the first sample: $a=0.25$ for Factor $1 ; a=0.58$ for Factor 2 . It is important to stress that cross-load removal improved the a indexes, making them achieve 0.61 for each factor. However, without cross loads, the model parameters are compromised.

\section{Psychometric properties analysis for the FRTolS}

Hull analysis suggested a one-dimensional solution. In the EFA ( $n=417$ ) with one factor extraction, four items showed factor loadings below 0.40 , and were eliminated from the analysis. The final analysis with one factor extraction returned adequate data for the single factor $[\mathrm{KMO}=0.84$; Bartlett's test of sphericity: $\mathrm{X}_{21,417}^{2}=538.1 ; \mathrm{p}<0.001$ ] (see Table 1 for statistical indices).

A second part of the database was analyzed with CFA. The initial model had satisfactory adequacy ratios $\left[X^{2}=49.937, d f=14(p<0.001) ; C F I=0.987 ;\right.$ TLI $=$ 0.981 ; RMSEA $(90 \% \mathrm{CI})=0.06(0.039-0.073) ;$ WRMR $=0.853]$. A model with all variables had significant regression weight. As shown in Figure 2, a one-factor solution was adequate, given the non-identification of grouping of items that made theoretical sense in factors, and the possibility of understanding all items as components of a general factor called risk tolerance.

\section{Evidence of convergent validity of the instruments}

Finally, the database was merged $(n=834)$ to analyze convergent validity of the scales. The initial model presented satisfactory adequacy ratios $\left[X^{2}=\right.$ 301.250, df = 84 ( $p<0.001) ;$ CFI = 0.956; TLI = 0.945 ; RMSEA $(90 \% \mathrm{CI})=0.056(0.049-0.063) ;$ WRMR $=1.289]$. A model with all variables had significant regression weight. As shown in Figure 3, FRTolS was significantly correlated with the FRTakS Spending money factor, but not with the FRTakS Investment factor.

Greater risk tolerance was associated with greater risk-taking in spending money. Furthermore, when the instruments were analyzed together, the direction of the relationship between risk factors changed (Figures 1 and 3). 


\section{Discussion}

EFA and CFA showed evidence of the validity of the internal structures of both instruments. However, the factor structures were different from the initial proposals.
Structure differences may have occurred because country conditions can widely influence risk taking and the risk tolerance. ${ }^{2,13}$ The different structures of the risk-taking scale and the risk tolerance scale in different countries are likely attributable to the facts that an individual's developmental history in different parts of

Table 1 - Factors extracted, factor loadings, communalities $\left(h^{2}\right)$, quantity of items, and variance explained for each factor, and reliability indexes (Cronbach's alpha) for FRTakS and FRTolS according to the oblique rotation method (PROMIN)

\begin{tabular}{|c|c|c|c|c|}
\hline \multirow[b]{2}{*}{ Items } & \multicolumn{2}{|c|}{ Factors of FRTakS } & \multirow[b]{2}{*}{$\begin{array}{l}\text { Factor of } \\
\text { FRTols } \\
- \text { F1 }\end{array}$} & \multirow[b]{2}{*}{$h^{2}$} \\
\hline & $\begin{array}{l}\text { F1 - } \\
\text { Spending } \\
\text { Money }\end{array}$ & $\begin{array}{l}\text { F2 - } \\
\text { Investments }\end{array}$ & & \\
\hline FRTakS 4. Spending money impulsively, without thinking about the consequences & 0.62 & & & 0.39 \\
\hline FRTakS 7. Using an overdraft & 0.63 & & & 0.40 \\
\hline FRTakS 8. Saving money for your retirement. & 0.58 & & & 0.33 \\
\hline FRTakS 13. Paying the credit card bill in installments & 0.53 & & & 0.37 \\
\hline FRTakS 6. Investing in a business that will not make immediate profit & & 0.59 & & 0.35 \\
\hline FRTakS 10. Taking a loan to invest in the financial Market & & 0.51 & & 0.31 \\
\hline $\begin{array}{l}\text { FRTakS } 11 \text {. Investing in a business that has a good chances of failing, but could } \\
\text { generate high profits. }\end{array}$ & & 0.67 & & 0.44 \\
\hline FRTakS 12 . Investing $50 \%$ of assets in stocks. & & 0.60 & & 0.36 \\
\hline $\begin{array}{l}\text { FRTolS } 1 \text { : In general, how would your best friend describe yourself as a risk taker? } \\
4 \text {. A real gambler; } 3 \text {. Willing to take risks after completing adequate research; } 2 \text {. } \\
\text { Cautious; } 1 \text {. A real risk avoider }\end{array}$ & & & 0.57 & 0.33 \\
\hline $\begin{array}{l}\text { FRTolS 3: If you unexpectedly received } \$ 20,000 \text { to invest, what would you do? } \\
\text { 1. Deposit it in a bank account, for any needs; } 2 \text {. Invest in savings account; } 3 \text {. } \\
\text { Invest it in safe high quality bonds or bond mutual funds; } 4 \text {. Invest it in stocks or } \\
\text { stock mutual funds. }\end{array}$ & & & 0.61 & 0.37 \\
\hline $\begin{array}{l}\text { FRTolS 4: In terms of experience, how comfortable are you investing in stocks or } \\
\text { stock mutual funds? } 1 \text {. Not at all comfortable; } 2 \text {. Uncomfortable; } 3 \text {. Somewhat } \\
\text { comfortable; } 4 \text {. Very comfortable }\end{array}$ & & & 0.71 & 0.51 \\
\hline $\begin{array}{l}\text { FRTolS 5: When you think of the word "risk" which of the following words comes to } \\
\text { mind first? } 1 \text {. Loss; } 2 \text {. Uncertainty; } 3 \text {. Opportunity; } 4 \text {. Thrill }\end{array}$ & & & 0.49 & 0.24 \\
\hline $\begin{array}{l}\text { FRTolS 8: Suppose a relative left you an inheritance of } \$ 100,000 \text {, stipulating in } \\
\text { the will that you invest ALL the money in ONE of the following choices. Which } \\
\text { one would you select? } 1 \text {. A savings account or money market mutual fund; } 2 \text {. A } \\
\text { mutual fund that owns stocks and bonds; } 3 \text {. A portfolio of } 15 \text { common stocks; } 4 \text {. } \\
\text { Commodities like gold, silver, and oil }\end{array}$ & & & 0.54 & 0.30 \\
\hline $\begin{array}{l}\text { FRTolS 9: If you had to invest } \$ 20,000, \text { which of the following investment choices } \\
\text { would you find most appealing? } 1.70 \% \text { in low-risk investments and } 30 \% \text { in } \\
\text { medium-risk investments; } 2.60 \% \text { in low-risk investments, } 30 \% \text { in medium-risk } \\
\text { investments and } 10 \% \text { in high-risk investments; } 3.30 \% \text { in low-risk investments, } \\
40 \% \text { in medium-risk investments and } 30 \% \text { in high-risk investments; } 4.10 \% \\
\text { in low-risk investments } 40 \% \text { in medium-risk investments } 50 \% \text { in high-risk } \\
\text { investments }\end{array}$ & & & 0.17 & 0.50 \\
\hline $\begin{array}{l}\text { FRTolS 10: Your trusted friend and neighbor, an experienced geologist, is putting } \\
\text { together a group of investors to fund an exploratory gold mining venture. The } \\
\text { venture could pay back } 50 \text { to } 100 \text { times the investment if successful. If the mine } \\
\text { is a bust, the entire investment is worthless. Your friend estimates the chance } \\
\text { of success is only } 20 \% \text {. If you had the money, how much would you invest? } 1 . \\
\text { Nothing; } 2 \text {. One month's salary; } 3 \text {. Three month's salary; } 4 \text {. Six month's salary }\end{array}$ & & & 0.44 & 0.19 \\
\hline Number of items & 4 & 4 & 7 & \\
\hline Variance explained \% & 26.74 & 25.70 & 43.61 & \\
\hline Cronbach's alpha & 0.51 & 0.67 & 0.74 & \\
\hline
\end{tabular}

FRTakS = Financial Risk-Taking Scale; FRTolS = Financial Risk Tolerance Scale; F1 = Factor 1; F2 = Factor 2. 
the world is a function of exposure to different societal norms and that individuals have different opportunities to engage in risky behaviors. ${ }^{13}$ The financial factor of the North American DOSPERT is composed of gambling and investment items. ${ }^{8}$ However, on the Brazilian risktaking scale, investment items were more important. ${ }^{6}$ In our study, investment items made up factor 2; and we found a culturally relevant factor called Spending Money. Previous research by Silva et al. ${ }^{11}$ corroborates the emergence of a Spending factor in Brazilian samples. The choice of spending or saving money, mainly in order to generate debts, can be considered risky, since it implies uncertainty in the future budget. These findings may suggest that hardships observed in the country, such as high infant mortality and more people below the poverty line ${ }^{14,15}$ tend to expose individuals to risks related to spending resource rather than to betting with these resources, since there are not always

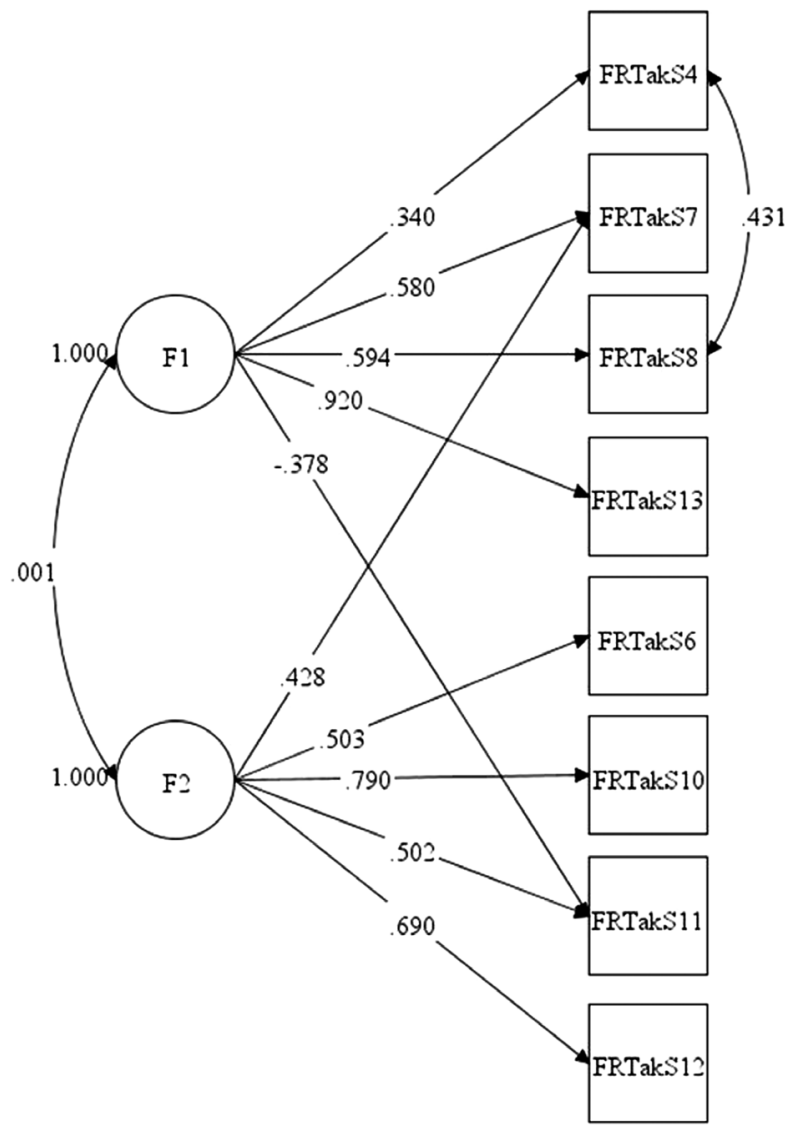

Figure 1 - Two-factor model for FRTakS obtained with a sample of 417 participants. Standardized estimates: regression coefficients close to unidirectional arrows and squared multiple correlations close to the variables. Extraction method: main axis factor. enough resources left to be wagered. ${ }^{13,14}$ It is important to remember that Brazilian law puts restrictions on gambling. ${ }^{20}$

Regarding the FRTolS, the greatest difference found between the instrument administered here and the original instrument were the three items that had responses added so that all items had four response choices. Notwithstanding, the scale did not exhibit the same factor structure found in Grable and Lytton's original version. ${ }^{5}$ It had been expected that FRTolS items would load onto Risk Investment and Risk Comfort \& Experience factors. In contrast, three items were excluded in the factor analysis and the remaining seven items were grouped onto just one factor, mixing items from the two factors predicted by the previous version of the scale. The reliability of the single risk tolerance factor was higher than the reliability reported in the original study. We note that this increase in the reliability

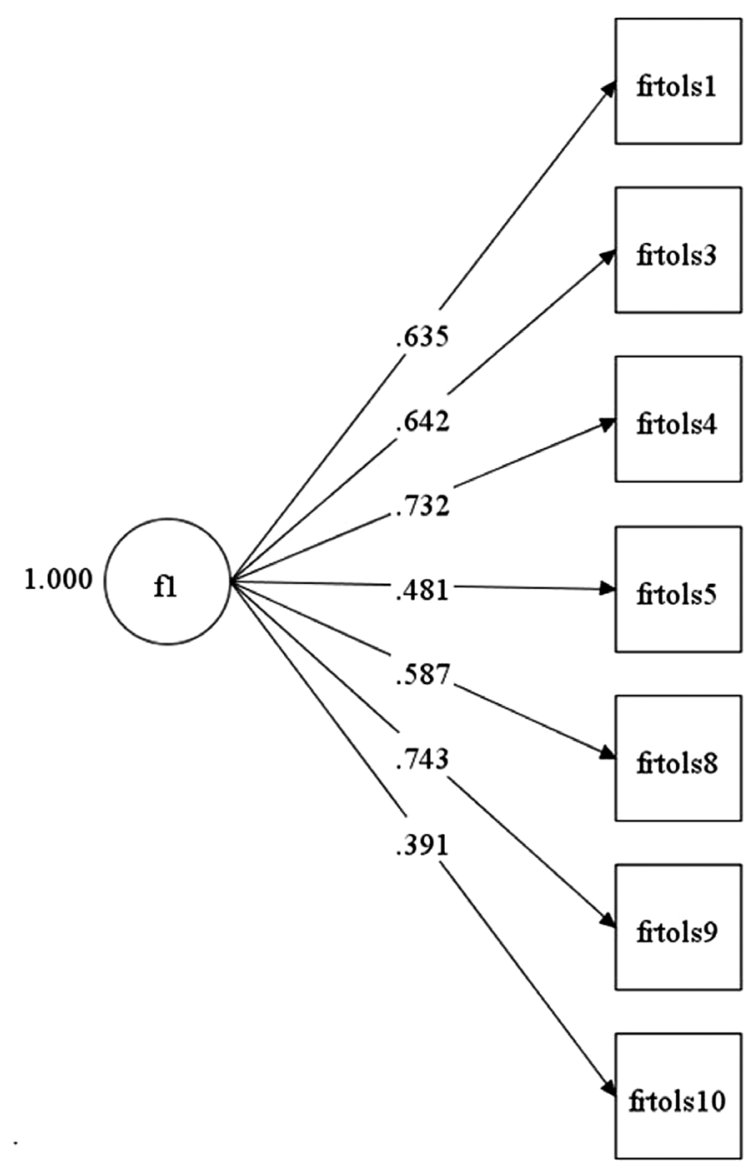

Figure 2 - Model for FRTolS obtained with a sample of 417 participants. Standardized estimates: regression coefficients close to unidirectional arrows and squared multiple correlations close to the variables. Extraction method: main axis factor. 
of the items could be related to the standardization of the answers implemented in this study; answers were presented in a randomized order in order to avoid application biases, and all items offered 4 response choices with scores ranging from 1 to 4 .

In our data, we observed that the correlation between FRTakS factors was significant and the direction of correlation was positive, when it was analyzed alone. However, the direction of correlation of the FRTakS factors became negative and non-significant when we included the FRTolS factor. Otherwise, the correlation between the FRTolS factor and the FRTakS Spending money factor was significant and positive and the correlation between the FRTolS factor and the FRTakS Investment factor was non-significant and positive. The positive correlation between FRTols and FRTakS factors corroborates previous research that showed this kind of relationship between these variables. ${ }^{3,4}$ Additionally, the negative correlation results found among risk-taking factors can be explained from the perspective of risk-specific domains, because these approaches do not understand risk as a general characteristic of the individual or the environment, but rather as a characteristic of specific contexts in which the greatest number of possible variables should be analyzed to understand the risk choice in a given situation. ${ }^{6,7}$ Analysis of tolerance and risk-taking factors together increases explanatory power and statistical efficiency, since it includes more information about the situation. ${ }^{19}$ We must consider that the robustness of the analysis is related to the quantity of variables that it encompasses.

Higher scores on the FRTakS Spending money factor correlated with higher scores on FRTolS and lower scores on the FRTakS Investment factor. Regarding the instruments, the FRTolS items deal with the subject of decisions on allocation of assets. ${ }^{12}$ Therefore, these items were related to how much a person accepts risky choices in the spending money context, but not in the investment context, indicating two different financial risk-taking domains in the same instrument.6,7 Thus, we recommend that future research using the FRTolS instrument should increase the number of items covering the issue of risk in investment.

In quantitative terms, FRTakS followed the pattern of reliability indexes shown in previous research with risk-taking scales in Brazilian samples ${ }^{6}$ and had slightly weaker reliability indexes than presented in studies with the original scale. ${ }^{8,9}$ This reliability contributes to restricting applications for use of the test. ${ }^{19}$ However, there is stability in the versions of risk-taking measures that present moderate indexes related to the reliability of the measure. This fact may not indicate a need to improve the items by reformulating them and/or adding new items to achieve good reliability indexes, as suggested in previous research.6,7 Rather, it may indicate the need to combine risk-taking instruments with other measures, like risk tolerance instruments, as we did in this paper, so that we have more comparative elements to support the results found.

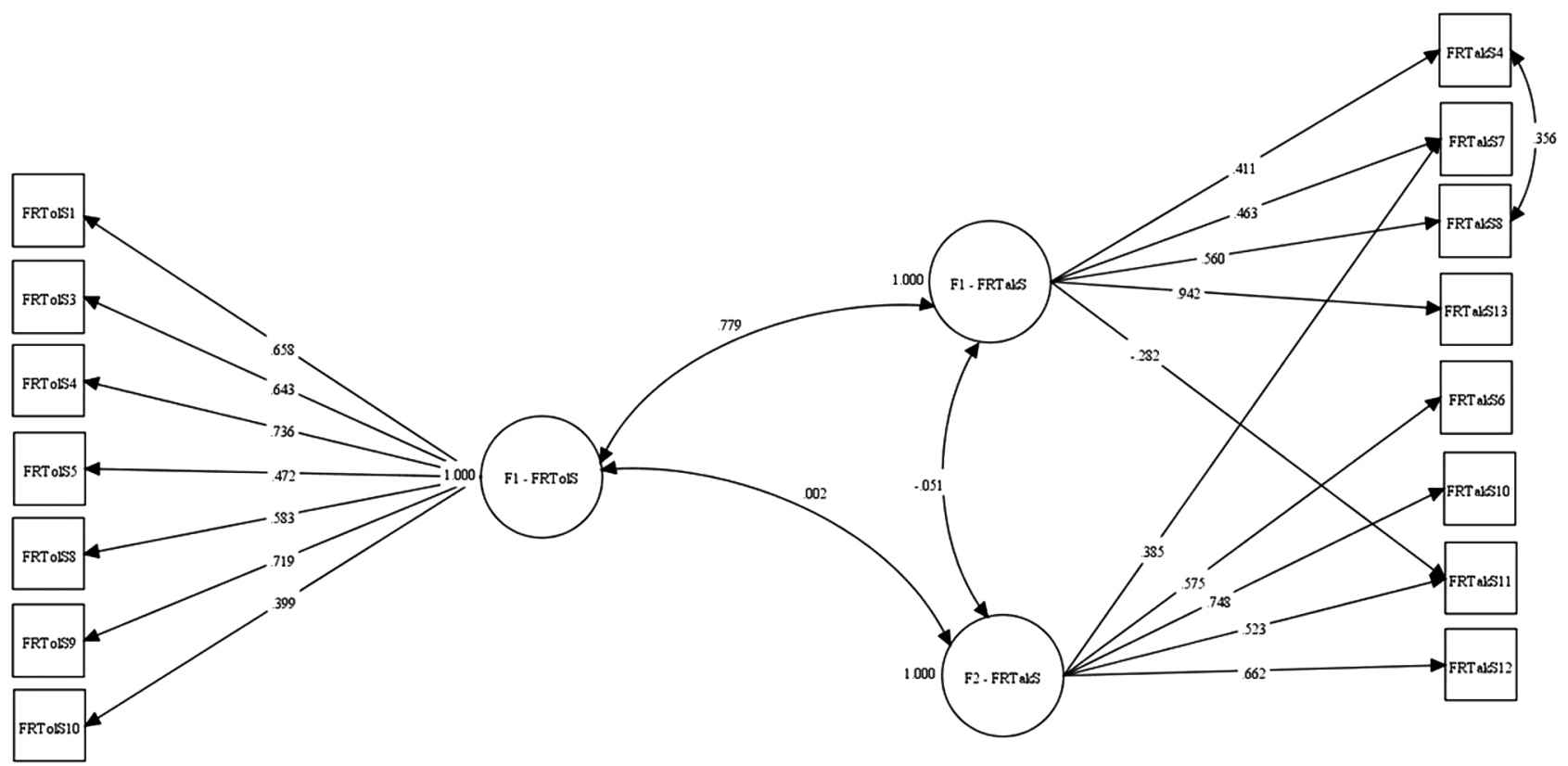

Figure 3 - Model of FRTolS and FRTakS factors tested, obtained with a sample of 834 participants. Standardized estimates: regression coefficients close to unidirectional arrows and squared multiple correlations close to the variables. Extraction method: main axis factor. 
It is important to note that one weakness of this study is that we worked with a convenience sample and our investor sample was restricted to economic classes $A$ and B. ${ }^{15}$ Future research should seek to understand how other economic classes deal with financial decisions, so that we can broaden the findings from this study to the Brazilian population in general. Additionally, Kannadhasan ${ }^{3}$ confirms this need by pointing to factors such as age, gender, educational level, and occupation as important in risk research, however, since our sample was homogeneous (males, mean age 43.3 years, and high educational level), we could not analyze the structure in different groups.

\section{Conclusion}

Studies of how people make decisions and the risk they tolerate and are willing to take in these decisions allow us to support strategies or programs designed to guide a decision-making process that suits the individual, institutional, and social levels of the decision-maker. ${ }^{4}$ We conclude that these instruments have presented good evidence of validity for use with Brazilian samples. The results suggest the existence of a two-dimensional factor structure for FRTakS and a one-dimensional factorial structure for FRTolS, and showed convergent validity between the two scales.

\section{Acknowledgements}

Jerson Laks has received research grants from Fundação de Amparo à Pesquisa do Estado do Rio de Janeiro (FAPERJ) and Conselho Nacional de Desenvolvimento Científico e Tecnológico (CNPq).

\section{Disclosure}

Jerson Laks has served as speaker for Eli Lilly, Servier, Novartis, Medley, Apsen, Lundbeck, Aché. No other conflicts of interest declared concerning the publication of this article.

\section{References}

1. Helfinstein $\mathrm{SM}$, Schonberg $\mathrm{T}$, Congdon $\mathrm{E}$, Karlsgodt $\mathrm{KH}$, Mumford JA, Sabb FW, et al. Predicting risk choices from brain activity patterns. Proc Natl Acad Sci U S A. 2014;111:2470-5.

2. Nobre LH, Grable JE, Silva WV, Veiga CP. A cross cultural test of financial risk tolerance attitudes: Brazilian and American similarities and differences. IJEFI. 2016;6:314-22.

3. Kannadhasan M. Retail investors' financial risk tolerance and their risk-taking behaviour: the role of demographics as differentiating and classifying factors. IIMB Manage Rev. 2015;27:175-84.

4. Grable J. Financial risk tolerance: a psychometric review. CFA Inst Res Foundation. 2017;4:1-20.

5. Grable J, Lytton RH. Financial risk tolerance revisited: the development of a risk assessment instrument. Financ Serv Rev. 1999;8:163-81.

6. Howat-Rodrigues ABC, Andrade AL De, Tokumaru RS. Development of a risk measure: specific risk-taking scale (EPRE). Psicol Teor Prat. 2013;15:175-93.

7. Howat-Rodrigues ABC, Andrade AL de, Tokumaru RS. Specific risk-taking scale -- evolutionary domains: adaptation and factorial structure. Aval Psicol. 2013;12:281-90.

8. Weber EU, Blais AR, Betz NE. A domain-specific risk-attitude scale: measuring risk perceptions and risk behaviors. J Behav Decis Making. 2002;15:263-90.

9. Blais AR, Weber EU. A domain-specific risk-taking (DOSPERT) scale for adult populations. Judgm Decis Mak. 2006;1:33-47.

10. Silva JG, Neto OSS, Araújo RCC. Educação financeira de servidores públicos: hábitos de consumo, investimento e percepção de risco. Rev Evid Cont Financas. 2017;5:104-20.

11. Gava AM, Vieira KM. Risco e gênero: medindo a tolerância ao risco e as diferenças entre os gêneros. Rev Cienc Admin. 2008;10:11438 .

12. Cavalheiro EA, Vieira KM, Ceretta PS. The determinants of risk tolerance: a behavioural analysis. Corp Ownership Control. 2012;9:476-85.

13. Duell N, Steinberg L, Icenogle G, Chein J, Chaudhary N, Di Giunta, $L$, et al. Age patterns in risk taking across the world. J Youth Adolesc. 2018;47:1052-72.

14. Mata R, Josef AK, Hertwig R. Propensity for risk taking across the life span and around the globe. Psychol Sci. 2016;27:231-43.

15. Associação Brasileira de Empresas de Pesquisa (ABEP). Brazilian Criteria 2015 and social class distribution update for 2016. 2015 [cited July 16 2018]. www.abep.org/criterio-brasil

16. Vieira PNRC. Attitudes towards risk in financial decision making (dissertation). Universidade de Lisboa: Instituto Superior de Economia e Gestão; 2016.

17. Lorenzo-Seva U. Promin: a method for oblique factor rotation. Multivariate Behav Res 1999;34:347-65.

18. Lorenzo-Seva U, Timmerman ME, Kiers HA. The Hull method for selecting the number of common factors. Multivariate Behav Res. 2011;46:340-64.

19. Marôco J. Análise de equações estruturais: fundamentos teóricos, software \& aplicações. $2^{a}$ ed. Lisboa: Report Number; 2014.

20. Brasil. Decreto-lei no 3.688. Lei das Contravenções Penais. 1941 [Internet]. [cited 2018 Jul 16]. www.planalto.gov.br/ccivil_03/ decreto-lei/Del3688.html

\section{Correspondence:}

Anna Beatriz Carnielli Howat-Rodrigues

Rua José Alexandre Buaiz, 190, sala 1509, Enseada do Suá

CEP 29050-918 - Vitória, ES - Brazil

Tel. : +55 (27) 999586026

E-mail: contato@howat-rodrigues.com.br 